\title{
Strength and Deformability of the Concrete Core of Precompressed Concrete Filled Steel Tube Columns of Annular Cross-Section
}

\author{
Anatoly Krishan ${ }^{1}$ and Mariia Astafeva ${ }^{2}$ \\ ${ }^{1}$ Full Professor, Doctor of Technical Sciences, Head of Department of Building Design and Constructions, Nosov Magnitogorsk State \\ Technical University, Uritsky, 11, Magnitogorsk 455000, Russia \\ ${ }^{2} \mathrm{PhD}$ Student of the Department of Industrial and Civil Engineering, Nosov Magnitogorsk State Technical University, Uritsky, 11, \\ Magnitogorsk 455000, Russia
}

\begin{abstract}
The advantages of short concrete filled steel tube columns with a precompressed concrete core are presented in the article. Particular cases, where such compression is most appropriate, are listed. Taking into consideration the structural features of concrete filled steel tube columns it is recommended to calculate their bearing capacity on the basis of deformation model of reinforced concrete. The reliability of this calculation will be largely dependent on the conformity of the accepted diagram of the concrete core deformation with its actual behavior. Formulas for determining the strength of precompressed concrete core and the ultimate strain of its shortening are proposed, which allow constructing the sufficiently accurate deformation diagram.
\end{abstract}

\section{Introduction}

Concrete filled steel tube columns (CFST) have significant constructive, technological, economic advantages and at the same time an architecturally expressive appearance [1-4]. Therefore, they are increasingly used in construction practice. In the process of CFST design it is recommended to ensure the reliable cooperation of the steel tube and the concrete core under operational loads. This is especially important in three cases.

The first case refers to the compressed elements behaving under conditions of cyclic loading by longitudinal force. According to the available experimental data $[5,6]$ the value of adhesion between concrete and steel is gradually decreasing under such conditions. When there is sufficiently large amount of loading cycles it often reaches zero. In these cases, in the absence of special anchors, the strength of contact between the concrete core and the shell is determined only by frictional forces. Special measures may be required to increase these forces.

The second case can be observed in columns of great flexibility. At the time of loss of columns bearing capacity, the axial stresses in the concrete may be substantially less than its strength. Then the behavior of concrete is regarded as quasi-elastic. Poisson's ratio for such concrete is about 0.2. Because Poisson's ratio of steel exceeds this value, the steel shell will begin to break away from the concrete. The strength of contact between the concrete core and the shell, which is caused only by adhesion in this case, may not be sufficient. As a result, isolated behavior of concrete and steel tube is possible which will have a negative effect on the bearing capacity of the structure [7-9].

The third case refers to the joint sections between concrete filled steel tube columns and load-bearing structures of the floor whose load is transferred to the column shaft only through the steel shell or only through the concrete core. Isolated behavior of concrete and steel tube is also possible at these sections.

Calculations show that sufficient shear strength can be ensured at compression of $1 \mathrm{MPa} \div 3 \mathrm{MPa}$ even when the adhesion between concrete and steel is equal to zero.

The proposed methods of precompression of the concrete core are presented in $[7,9,10]$. The carried out analysis shows that the application of concrete mix longterm pressing by pushing two or three steel tubes into it along the guide located coaxially towards the external steel shell is the most effective. After the fabrication of the element the last tube is left as its internal rod.

The application of concrete mix long-term pressing by means of this technology allows improving the concrete core structure. In the process of pressing the thickness of the cement interlayer between the aggregate grains decreases, a fine-grained structure of a cement stone of better quality with significantly smaller pore sizes is obtained. All of the above makes it possible to significantly increase the strength of the initial concrete. In our experiments [10] the pressing pressure was $2 \mathrm{MPa}$ $\div 3 \mathrm{MPa}$. At the same time, the strength of concrete increased by about $50 \div 60 \%$. In addition, the pressing pressure transferred through the concrete mix generates preliminary tensile stresses in circumferential direction of 
the steel shell. As a result, the conditions for volumetric compression of the concrete core under any level of applied external load can be created.

Thus, the design of a CFST column consisting of external and internal steel tubes with precompressed concrete located between them (Figure 1) is proposed. The literature review demonstrates that there are no proposals for determining the bearing capacity of such columns.

The article [4] shows that the most reliable definition of the bearing capacity of CFST columns is possible on the basis of the calculations using the deformation model of reinforced concrete. These calculations are based on deformation diagrams of materials. The most complicated problem is associated with the construction of the diagram of deformation of the concrete core. In this case, it is necessary to take into account the behavior of pressed concrete operating under volumetric compression. At the same time, the stress-strain state of concrete constantly varies as the level of external compression load increases.

The form of the concrete deformation diagram is assumed to be curvilinear with a falling branch. Numerical construction of this diagram is possible using the multipoint method [11]. It is obvious that the design parameters of the concrete axial deformation diagram " $\sigma_{\mathrm{cz}}-\varepsilon_{\mathrm{cz}}$ " are largely determined by the coordinates of its vertex - the strength of the volumetrically compressed concrete $f_{\mathrm{cc}}$ and the strain $\varepsilon_{\mathrm{cc} 1}$ (Figure 3). Their calculation formulas are presented below.

\section{Strength of the concrete core}

The increase of concrete core strength of precompressed samples of CFST columns is determined by the display of three known effects - long-term pressing of the concrete mix, lateral precompression of the concrete core and its behavior under volumetric compression conditions.

The formula obtained in the article [4] is proposed to be used for determining the strength of the pressed concrete:

$$
f_{\mathrm{cp}}=f_{\mathrm{c}}(1+0,3 \alpha \sqrt{P}),
$$

where $f_{\mathrm{c}}$ is the concrete compressive strength;

$\alpha \leq 1$ is the coefficient depending on the composition of the concrete mix;

$P$ is the value of effective pressing pressure which is calculated by using the formula:

$$
P=\Delta f \cdot \sigma_{\mathrm{cr} 0},
$$

in which $\Delta f$ is the correction factor taking into account the decrease of long-term pressing efficiency as the strength of the initial concrete increases. It is determined by the following empirical formula:

$$
\Delta f=4,4 / \sqrt{f_{\mathrm{c}}} .
$$

In the formulas $(1 \div 3) P, \sigma_{\mathrm{cr} 0}$ and $f_{\mathrm{c}}$ are expressed in $\mathrm{MPa}$. These formulas underwent practical verification for C20 $\div$ C50 concrete grades. The value of coefficient $\alpha$ is recommended to be verified by testing the standard samples of the initial and pressed concrete.
The strength of volumetrically compressed concrete is largely dependent on the relation of axial and transverse stresses arising in it. In the centrally compressed CFST element of circular cross-section the circumferential

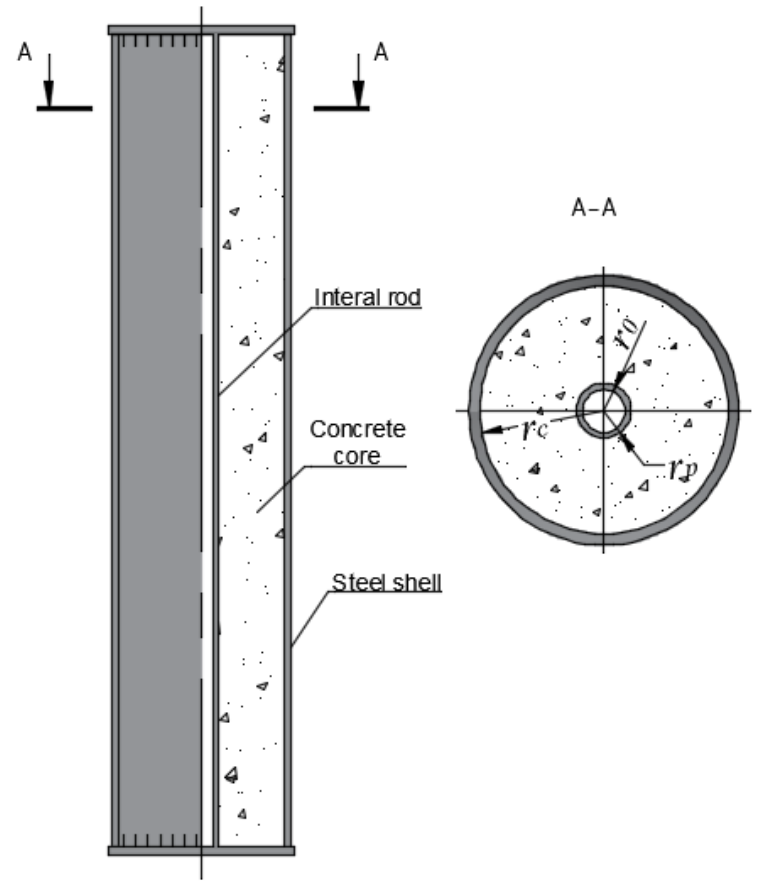

Figure 1. Concrete filled steel tube column structure

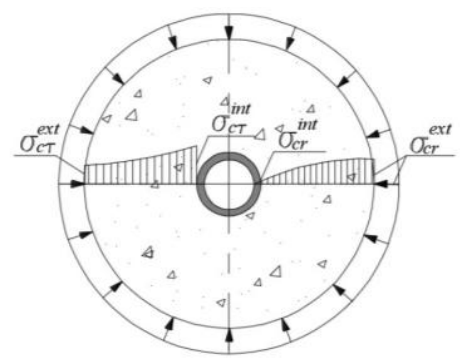

Figure 2. Distribution of transversal stresses across the crosssection of the concrete core

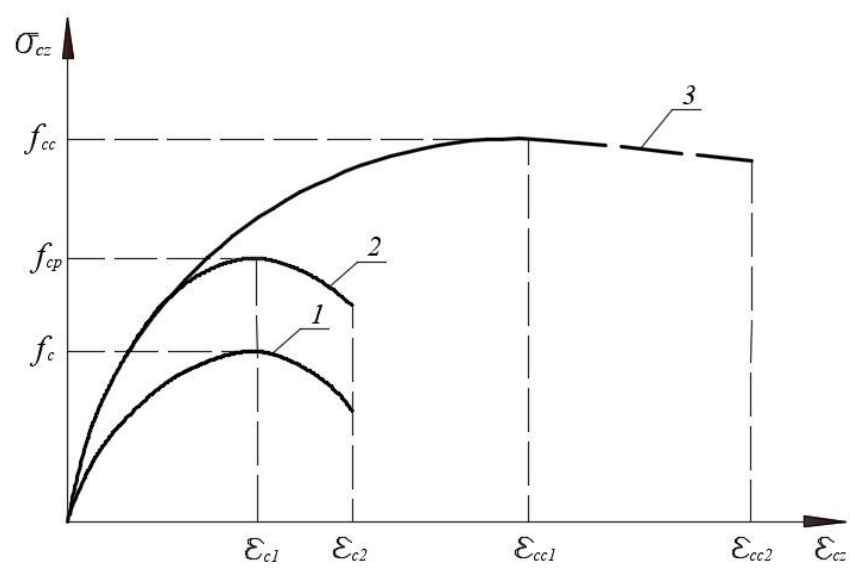

Figure 3. Deformation curves for uniaxially compressed concrete (1), for similar pressed concrete (2) and for volumetrically compressed concrete core of CFST (3) 
stresses $\sigma_{\text {cr }}$ across the cross-section of the concrete core are equal to the radial stresses $\sigma_{\text {cr }}$ which are determined by the value of lateral pressure applied on the concrete by the steel shell and calculated at the point of their contact $\sigma_{\mathrm{cr}}^{\mathrm{ext}}$. Taking into account the results of the paper [4], the lateral pressure $\sigma_{\mathrm{cr}}^{\mathrm{ext}}$ in the limiting state of the CFST column made of heavy concrete can be determined by formula

$$
\sigma_{\mathrm{cr}}^{\mathrm{ext}}=0,33 \xi^{0,8} f_{\mathrm{cp}}
$$

where $\xi$ is the constructive coefficient, calculated by using the formula

$$
\xi=\frac{f_{\mathrm{y}, \mathrm{p}} A_{\mathrm{p}}}{f_{\mathrm{cp}} A},
$$

in which $f_{\mathrm{y}, \mathrm{p}}$ is a yield stress of the steel holder; $A$ and $A_{\mathrm{p}}$ are cross-section areas of the concrete core and the steel holder.

The radial and tangential stresses across the crosssection of the structure in the compressed CFST elements of annular cross-section with a hollow steel tube will be variable (Figure 1, b). Formulas for determining their values, taking into account the well-known Lyame solution, are suggested to be written in the following form:

$$
\begin{gathered}
\sigma_{\mathrm{cr}}=m_{\mathrm{c}}-n_{\mathrm{c}} / r^{2} \\
\sigma_{\mathrm{c \tau}}=m_{\mathrm{c}}+n_{\mathrm{c}} / r^{2}
\end{gathered}
$$

where $r$ is the current radius.

The following formulas for calculating the parameters $m_{\mathrm{c}}$ and $n_{\mathrm{c}}$ are obtained in the article [4] :

$$
\begin{gathered}
m_{\mathrm{c}}=\sigma_{\mathrm{cr}}^{\mathrm{ext}}\left(p_{5} E_{\mathrm{p}} / E_{\mathrm{cp}}+p_{2} p_{3}\right) /\left(p_{4} E_{\mathrm{p}} / E_{\mathrm{cp}}-p_{1} p_{3}\right) ; \\
n_{\mathrm{c}}=\left(m_{\mathrm{c}}-\sigma_{\mathrm{cr}}^{\mathrm{ext}}\right) \cdot r_{\mathrm{c}}^{2},
\end{gathered}
$$

in which $E_{\mathrm{cp}}$ and $E_{\mathrm{p}}$ are the moduli of elasticity of pressed concrete and internal steel tube, and the remaining components are calculated by using the following dependencies:

$$
\begin{aligned}
p_{1}= & \left(r_{\mathrm{p}}^{2}-r_{\mathrm{c}}^{2}\right) /\left(r_{\mathrm{p}}^{2}-r_{0}^{2}\right) ; \\
& p_{2}=r_{\mathrm{c}}^{2} /\left(r_{\mathrm{p}}^{2}-r_{0}^{2}\right) ; \\
p_{3}= & \left(1+\vartheta_{\mathrm{p}}\right)\left(1-2 \vartheta_{\mathrm{p}}+r_{0}^{2} / r_{\mathrm{p}}^{2}\right) ; \\
p_{4}= & \left(1+\vartheta_{\mathrm{c}}\right)\left(1-2 \vartheta_{\mathrm{c}}+r_{\mathrm{c}}^{2} / r_{\mathrm{p}}^{2}\right) ; \\
& p_{5}=\left(1+\vartheta_{\mathrm{c}}\right) r_{\mathrm{c}}^{2} / r_{\mathrm{p}}^{2} .
\end{aligned}
$$

In the above formulas, $r_{\mathrm{c}}$ and $r_{0}$ are the radii of the cross-section of the concrete core and the internal steel tube; $\vartheta_{c}$ and $\vartheta_{p}$ are transverse deformation coefficients of the concrete core and the internal steel tube.

During the calculation of CFTC strength, the stressstrain state of the concrete core and the steel shell is largely determined by the ratio of concrete and steel transverse deformation current coefficients. That is why their precise definition is of fundamental importance.

The values of concrete transverse deformation coefficients with the increase of compressive stress level increase from the initial ones $\vartheta_{\text {co }}=0,18 \div 0,25$ to the extreme ones $\vartheta_{c u}$ at the top of the deformation diagram.
It is offered to calculate coefficients $\vartheta_{c}$ depending on the current $v_{c}$, the initial $v_{\text {co }}$ and the extreme $v_{c u}$ values of the concrete elasticity coefficient according to the formula:

$$
\vartheta_{c}=\vartheta_{c u}-\left(\vartheta_{c u}-\vartheta_{\mathrm{co}}\right)\left(\frac{\nu_{c}-\nu_{c u}}{\nu_{\mathrm{co}}-v_{c u}}\right)^{0,5},
$$

in which the extreme value of transverse strain coefficient $\vartheta_{c u}$, as well as the coefficients of elasticity can be determined according to the recommendations of the paper [4].

The value of the coefficient of transverse deformation for a steel shell $\vartheta_{p}$ is proposed to be determined by the formula:

$$
v_{p}=0,48-\left(0,48-\vartheta_{\mathrm{po}}\right)\left(\frac{v_{p}-v_{p u}}{v_{\mathrm{po}}-v_{p u}}\right),
$$

in which $v_{\mathrm{po}}$ and $v_{p u}$ are the coefficients of elasticity at the beginning of the deformation diagram and at the end of the yield point; $\vartheta_{\mathrm{po}}$ is Poisson's ratio for steel $\left(\vartheta_{\text {po }} \approx 0,3\right)$.

The coefficients of elasticity $v_{p}, v_{\mathrm{po}}$ and $v_{p u}$ can be determined according to the recommendations of the paper [4].

The values of $\vartheta_{p}$, calculated by the formula (16), are in good agreement with the data of the Russian Federation standards (Construction Rules and Regulations $2.05 .06-85^{*}$ ), but at that the calculations through elastic coefficients make it possible to get rid of additional iterations in the process of practical implementation of the deformation model.

The pattern of transversal stresses distribution across the cross-section of the concrete core (Figure 2) testifies that this is the general case of volumetric compression, where $\left|\sigma_{\mathrm{cz}}\right|>\left|\sigma_{\mathrm{c \tau}}\right|>\left|\sigma_{\mathrm{cr}}\right|$. For such a case with a small error the influence of intermediate stress $\sigma_{\mathrm{c} \tau}$ on the strength of concrete under volumetric compression can be neglected.

In this setting, the longitudinal force in the concrete core $N_{\mathrm{c}}$ for CFST of annular cross-section with an internal steel tube is expressed by the following dependence:

$$
N_{\mathrm{c}}=\int_{r_{p}}^{r_{b}}\left[f_{\mathrm{cp}}+k\left(m_{\mathrm{c}}-n_{\mathrm{c}} / r^{2}\right)\right] 2 \pi r \mathrm{~d} r,
$$

where $k$ is the coefficient of lateral pressure [12].

The same force can be expressed in terms of the value of lateral pressure $\sigma_{\text {crm }}$ averaged over the cross-section of the concrete. Then the formula for determining $N_{\mathrm{c}}$ can be written in the following form:

$$
N_{\mathrm{c}}=\left(f_{\mathrm{cp}}+k \sigma_{\mathrm{crm}}\right) \cdot \pi \cdot\left(r_{\mathrm{c}}^{2}-r_{0}^{2}\right) .
$$

From the equality of the right-hand sides of the equations (17) and (18), after carrying out appropriate transformations, the formula for determining the averaged pressure can be obtained: 


$$
\sigma_{\mathrm{crm}}=\sigma_{\mathrm{cr}}^{\mathrm{ext}} K_{\mathrm{r}}
$$

in which the parameter $K_{r}$ is determined depending on the geometric and deformative characteristics of the concrete core and the internal steel tube:

$$
K_{\mathrm{r}}=p_{0}\left(1-2 \ln \frac{r_{\mathrm{b}}}{r_{\mathrm{c}}}\right)+2 \ln \frac{r_{\mathrm{c}}}{r_{\mathrm{p}}},
$$

where

$$
p_{0}=\left(p_{5} E_{\mathrm{p}} / E_{\mathrm{c}}+p_{2} p_{3}\right) /\left(p_{4} E_{\mathrm{p}} / E_{\mathrm{cp}}-p_{1} p_{3}\right)
$$

and the parameters $p_{1} \div p_{5}$ are calculated by using the formulas $(10 \div 14)$.

The averaged compressive strength of the concrete core of precompressed CFST columns of annular crosssection can be determined in a similar way to the columns of circular cross-section [4]. The following formula is used for this purpose:

$$
\begin{aligned}
& f_{\mathrm{cc}}=f_{\mathrm{cp}}\left[1+\left(0,5 \bar{\sigma}_{\mathrm{m}}+\frac{\bar{\sigma}_{\mathrm{m}}-2}{4}+\sqrt{\left(\frac{\bar{\sigma}_{\mathrm{m}}-2}{4}\right)^{2}+\frac{\bar{\sigma}_{\mathrm{m}}}{b}}\right)\right], \\
& \text { where } \bar{\sigma}_{\mathrm{m}}=\sigma_{\mathrm{crm}} / f_{\mathrm{cp}} .
\end{aligned}
$$

\section{Axial strain of the concrete core}

Another coordinate of the vertex of the concrete core deformation diagram is the axial strain $\varepsilon_{\mathrm{ccl}}$ at the peak stress $f_{\text {cc }}$ and limiting deformations preceding the destruction of concrete $\varepsilon_{\mathrm{cc} 2}$ (Figure 3). For CFST column the value of such strain must be determined taking into account the volumetric stress state of concrete.

The published experimental data indicate higher deformability of CFST columns. There are many proposals for determining deformations $\varepsilon_{\mathrm{cc} 1}$ and $\varepsilon_{\mathrm{cc} 2}$ in the literature. Some of them are presented in [3, 13-20]. Most researchers recommend using the following formula

$$
\varepsilon_{\mathrm{cc} 1}=\varepsilon_{\mathrm{c} 1}\left(1+k \frac{\sigma_{\mathrm{cr}}}{f_{\mathrm{c}}}\right),
$$

where $\varepsilon_{\mathrm{c} 1}$ is the deformation at the maximum stress of uniaxial compressed concrete;

$\sigma_{\text {cr }}$ is lateral pressure on concrete due to the presence of indirect reinforcement.

The coefficient values are usually taken in the range from 17.5 [20] to 20.5 [17].

In the case of circular pipe-shaped columns, European norms (EN 1992-1-1. Eurocode 2: Design of Concrete Structures) suggest another formula

$$
\varepsilon_{\mathrm{cc} 1}=\varepsilon_{\mathrm{cl}} \cdot\left(\frac{f_{\mathrm{cc}}}{f_{\mathrm{c}}}\right)^{2} .
$$

The magnitude of the limiting strain $\varepsilon_{\mathrm{cc} 2}$ is also determined by empirical coefficients, for example, according to the following formula

$$
\varepsilon_{\mathrm{cc} 2}=5,5 \varepsilon_{\mathrm{c} 2},
$$

where $\varepsilon_{\mathrm{c} 2}$ is the ultimate deformation of uniaxial compressed concrete.
The authors considered the diagram of volumecompressed concrete deformation (a curve 3 in figure 3) corresponding to the maximum reached stress and compared it with the uniaxial pressed concrete diagram. It follows from the above that the initial modulus of elasticity for both diagrams is the same.

The total deformation at the vertex of this diagram can be regarded as the sum of the elastic and plastic components

$$
\varepsilon_{\mathrm{cc} 1}=\varepsilon_{\mathrm{el}}+\varepsilon_{\mathrm{pl}} .
$$

The elastic part of the total deformation, taking into account the assumed equality of the volume-compressed and uniaxial pressed concrete modulus of elasticity, is determined with formula

$$
\varepsilon_{\mathrm{el}}=\varepsilon_{\mathrm{el}}^{\prime} \cdot \frac{f_{\mathrm{cc}}}{f_{\mathrm{cp}}},
$$

where $\varepsilon_{\mathrm{el}}^{\prime}$ is the elastic part of the deformation $\varepsilon_{\mathrm{c} 1}$.

It is obvious that the plastic part of the total deformation $\varepsilon_{\mathrm{pl}}$ can also be expressed by corresponding component of the total deformation at the top of the uniaxial pressed concrete $\varepsilon_{\mathrm{pl}}^{\prime}$. and the ratio $f_{\mathrm{cc}} / f_{\mathrm{cp}}$. The volume-compressed concrete deformability is more intensive than the strength growth (see formula (2)), so the formula for determination is written in the following way:

$$
\varepsilon_{\mathrm{pl}}=\varepsilon_{\mathrm{pl}}^{\prime} \cdot\left(\frac{f_{\mathrm{cc}}}{f_{\mathrm{cp}}}\right)^{\mathrm{m}},
$$

where $m$ is the exponent, $\mathrm{m}>1$.

The plastic part of the deformation at the top is determined by the formula

$$
\varepsilon_{\mathrm{pl}}^{\prime}=\varepsilon_{\mathrm{cl}}-\frac{f_{\mathrm{cp}}}{E_{\mathrm{cp}}},
$$

where $E_{\mathrm{cp}}$ is the initial modulus of elasticity of pressed concrete.

Thus, the total deformation of the volume-compressed concrete at the maximum stress is determined by the formula

$$
\varepsilon_{\mathrm{cc} 1}=\varepsilon_{\mathrm{c} 1}\left(\frac{f_{\mathrm{cc}}}{f_{\mathrm{cp}}}\right)^{\mathrm{m}}+\frac{f_{\mathrm{cc}}}{E_{\mathrm{cp}}}-\frac{f_{\mathrm{cp}}}{E_{\mathrm{cp}}}\left(\frac{f_{\mathrm{cc}}}{f_{\mathrm{cp}}}\right)^{\mathrm{m}} .
$$

The performed statistical analysis showed that the best match with the results of the experiments corresponds to a value of $\mathrm{m} \approx 2.5$. Therefore, the final formula for determining the longitudinal deformation at the top of the volume-compressed concrete deformation diagram is written as

$$
\varepsilon_{\mathrm{cc} 1}=\alpha_{\mathrm{c}}\left[\varepsilon_{\mathrm{c} 1} \alpha_{\mathrm{c}}^{1,5}-\frac{f_{\mathrm{cp}}}{E_{\mathrm{cp}}}\left(\alpha_{\mathrm{c}}^{1,5}-1\right)\right],
$$

where $\alpha_{\mathrm{c}}$ is the coefficient of concrete strength increase due to volume compression $\left(\alpha_{\mathrm{c}}=f_{\mathrm{cc}} / f_{\mathrm{cp}}\right)$.

It follows from formula (31) that the value of strain $\varepsilon_{\mathrm{ccl}}$ depends on such factors as compressive strain in the pressed concrete at the peak stress $\varepsilon_{\mathrm{cl}}$, coefficient $\alpha_{\mathrm{c}}$, axial compressive strength of the pressed concrete $f_{\text {cp }}$ and 
its initial modulus of elasticity $E_{\mathrm{cp}}$. According to the data of the papers [21, 22], the deformation of pressed concrete can be assumed to be equal to the analogous deformation of heavy concrete.

The value of the initial modulus of elasticity of pressed concrete $E_{\mathrm{cp}}$ increases as the effective pressing pressure $P$ grows but to a lesser extent than concrete strength. According to our experiments, when $\mathrm{P}$ varies in the range from $0.7 \mathrm{MPa}$ to $4 \mathrm{MPa}, E_{\mathrm{cp}}$ increases by 10 $20 \%$. It is logical to assume that the value of the modulus of elasticity $E_{\mathrm{cp}}$ depends on the characteristic strength of the pressed concrete. The following formula, based on the results of statistical analysis of experimental data, is obtained in the article [4]:

$$
E_{\mathrm{cp}}=56-\frac{108}{\sqrt{f_{\mathrm{ck}}\left(1+0,3 \alpha P^{0,5}\right)}},
$$

where $f_{c k}$ is the characteristic strength of the initial (non-pressed) concrete.

Relative deformation at the end of the deformation diagram of a volume-compressed concrete core, according to the recommendations of [4], is determined by the formula

$$
\varepsilon_{c c 2}=\varepsilon_{c 2} \frac{\varepsilon_{c c 1}}{\varepsilon_{c 1}} .
$$

When the strength of volumetrically compressed concrete $f_{\mathrm{cc}}$, the strain $\varepsilon_{\mathrm{cc} 1}$ and $\varepsilon_{c c 2}$ are known, it is possible to construct the deformation diagram (EN 19921-1), which can be used for calculating the bearing capacity of CFST columns based on the deformation model analysis.

\section{Conclusion}

Dependences for determining the strength and the ultimate axial strain of the concrete core of precompressed CFST columns of annular cross-section were obtained on the basis of the phenomenological approach. The use of such dependencies allows constructing the diagram of deformation of volumetrically compressed concrete core with sufficient practical accuracy which enables to calculate the bearing capacity of CFST columns using the deformation model.

\section{Acknowledgments}

The article is written on the basis of the results of the research conducted by the Ministry of Education and Science of the Russian Federation No. 7.3379.2017 / PP.
1. I. Nishiyama, S. Morino, K. Sakino, and H. Nakahara, Japan Cooperative Research Program on Composite and Hybrid Structures, Japan, (2002) p.176

2. B Chen, Long span CFST arch bridges: Chinesecroatian joint colloquium, Brijuni islands, (2008) pp. 357-368.

3. A. M. Fattah, Grand PhD in (Philosophy) sciences, USA (Kanzas State University, 2012) pp. 399.

4. A. L. Krishan, M. A. Astafeva, and R.R. Sabirov Monograph. (Saarbrucken, Deutschland: Palmarium Academic Publishing, 2016), p. 261.

5. R. Bergmann, C. Matsui, Meinsma, and D. Dutta, (Verlag TUV Rheinland, Germany, 1995), p. 68.

6. F. Zhou and W. Xu, Engineering Structures. 127, pp. 304-318 (2016)

7. A. L. Krishan, Appl. Opportunities: Proceedings of the International Conference held at the University of Dundee, pp. 725-733 (2005)

8. L. H. Han, (Beijing: China Science press, 2007), p. 118.

9. A. L. Krishan, Monograph. (Rostov-on-Don: Rostov state building university, 2011), p. 372.

10. A. L. Krishan, Grand PhD in (Technical) sciences. (Nosov Magnitogorsk State Technical University, 2011), p. 335.

11. N. I. Karpenko, S. N. Karpenko, A. N. Petrov, and S. N. Palyuvina, (Petrozavodsk: Publishing house PetrSU, 2013), p.156.

12. N. I. Karpenko, (Moscow: Stroyizdat, 1996) p. 416.

13. S. Popovich, Journal Cement and Concrete Research, 3(5), pp.583-659 (1973)

14. M. Saatcioglu and S.R. Razvi, "Journal of Structural Engineering, 118(6), pp. 1590-1607 (1992)

15. I. Imran and S. J. Pantazopoulou, ACI Materials Journal, 93(6), pp. 562-573 (1996)

16. S. P. Marques, D. C. Marques, and J.L. Silva, Journal of Composite Constructions, 8(4), pp. 332340 (2004)

17. J. B. Mander, M. J. N.Priestley, and R.Park, Journal of Structural Engineering, 114(8), pp. 1804-1826, ASCE (1988)

18. Q. Q. Liang and S. S. Fragomeni, Journal of Constructional Steel Research, 66, pp.159-169 (2010)

19. A. Xiamuxi and A. Hasegawa, Journal of Constructional Steel Research, 76, pp.144-154 (2012)

20. Fafitis A and Shah S P, ACI Materials J. 87(12) pp 212-32 (1985)

21. G. V. Murashkin, Reinforced concrete structures, pp. 5-20, (Kuibyshev: KSU, 1984)

22. A. L. Krishan, M. A. Astafeva, M. Yu. Narkevich, and V. I. Rimshin, Natural and technical sciences, 910 (77), pp. $367-369$ (2014)

\section{References}

